\title{
Research on Bilingual Teaching in Engineering Based on Problem-oriented Teaching Method
}

\author{
LIU Yang, LYU Jie, LYU Dan, GUO Shijun, PENG Anmin \\ Shanghai University of Medicine \& Health Sciences \\ No. 279, Zhouzhu Road, Pudong New Area, Shanghai, 201318 \\ Email: liuy@sumhs.ed.cn
}

\begin{abstract}
With the continuous improvement of China's opening to the outside world, the demand for compound talents who are both good at professional knowledge and proficient in foreign languages is becoming more and more prominent. Higher requirements are put forward against the innovative higher education and personnel training, especially bilingual talents training. In this paper, the problem-oriented teaching method is adopted, while in combination with the characteristics of engineering curriculums, the specific methods of bilingual teaching are also explored, to provide a reference for the bilingual teaching process design in the engineering.
\end{abstract}

Keywords-problem-oriented teaching method; bilingual teaching; engineering curriculums; higher education

\section{INTRODUCTION}

With the deepening of the process of globalization, China's rising international status, the "Step Out" education trend is obvious, especially in the context of "Belt and Road", the Ministry of Education has introduced a document regarding Promotion of Co-construction of 'Belt and Road' Educational Program which clearly pointed out that through the full play of a positive role of education "Soft Power" to promote the realization of "Belt and Road" construction, the limitations of the teaching language is increasingly prominent. Moreover, for the urgency, with the "Made in China 2025" strategy of becoming a powerful country moves forward constantly, the internationalization of the engineering technology personnel have become inevitable in which trend [1], new questions and challenges are proposed against the bilingual training of the engineering technology personnel. In this case, how to design and build bilingual teaching methods and research in the engineering based on the practice and problem-solving appears to be important and urgent. This paper will present the research and discussion on the problem-oriented engineering technology teaching methods through the analysis of the current status and the professional characteristics.

\section{ANALYSIS OF BILINGUAL TEACHING}

The bilingual teaching has higher requirements of the teaching system allocation and design, including teachers, curriculum PPT, teaching materials and students. Most of the schools in China lack English language environment, and the main language of teaching is the Chinese; although many schools and professional fields have carried out "bilingual teaching", but from the current domestic schools which carrying out the bilingual teaching and its supporting teaching system, the number of the schools adopting the bilingual professional teaching is relatively small, and most focuses on humanity majors like the management and finance. There are three main reasons for the current situation as follows:

\section{A. Foreign language application ability of the teachers remains to be improved.}

At present, the vast majority of professional teachers in China are limited in English application ability, especially the engineering teachers who have little opportunities to apply the foreign language and weak oral organization ability; and in the face of professional curriculums, the teaching ability in foreign language is limited. Moreover, a few of teachers can really be fluent in the classroom to use English to describe the concepts of engineering. Although they publish their academic papers, especially on international journals, Chinese teachers' English application ability has been greatly improved, but most of aspects are reflected in English reading and English writing; for the English applied in daily teaching, especially needing interaction with students in the practice curriculum, the correctness and normality of English expression remain to be improved.

\section{B. Selection and application of teaching materials remain to be considered}

The teaching materials selection of the bilingual teaching is particularly important, and the textbooks in English have to be adopted. There is no standard in different professional and at different levels. Therefore, the scope and method of the selection of teaching materials will face some difficulties: for the scope, there is difference among the countries adopting English for teaching in the authority of the different professionals, whether the US textbooks or British textbooks, even also refer to German textbooks in some engineering areas; for the method, whether fully introduce the original textbooks or interception of the original textbooks, and even translate the Chinese textbooks into English textbooks, are not determined. Due to the problems in these aspects, we have to think carefully of the selection and application of the bilingual teaching materials. 


\section{Teaching evaluation measures remain to be unified.}

There should be a corresponding evaluation system and mechanism for the teaching effect, but from the particularity of bilingual teaching, the evaluation mechanism of teaching should also take into account the characteristics of the bilingual teaching. So an evaluation mechanism reflecting the professional knowledge and the characteristics of foreign language application related such knowledge is needed to be established. At the same time, based on the bilingual teaching background, such evaluation system and mechanism should be in line with international standards and also comply with internationally recognized relevant standards and professional standards. However, in the curriculum of practice, because the many kinds of curriculum complying with the international standards and professional standards are not clear, the evaluation criteria of the bilingual curriculum tends to have "pay emphasis on the language; contempt for professional" phenomenon, and then deviate from the actual goal of curriculum settings.

\section{Problem-ORIENTED TEACHING Methods}

The teaching idea of the problem-oriented teaching method was firstly proposed by the American educator John Dewey, that is to say, the teachers create a natural instinct by guiding their students, inspiring their students to explore the knowledge by themselves and master their knowledge. The theory is put forward: based on the students' cognitive rules, teachers contacting teaching experience, and design and adjustment of the curriculum contents and teaching process, to stimulate students' interest in the study and to enhance learning initiative to the greatest degree. The problem-oriented teaching theory holds that the problem-solving solution is the learning goal, on which based, select the learning path, construct the knowledge base and select the corresponding learning method. The engineering curriculums are engineering-based, with strong logical application and multiple derivation formula operation of concepts. Therefore, the problem-oriented learning and teaching should take into account the professional characteristics, that is, the practical engineering problems are taken as a problem carrier, while the teachers guide the students and the students give comprehensive consideration and finally propose the solution through data retrieval, investigation \& survey, group discussions and other open learning methods. And ultimately, master the relevant knowledge and form a professional knowledge system and the teaching methods for the occupation capacity through thinking, sorting and the application. The acquisition process is summarized as follows: "raise questions - think about questions - make analysis and research - solve problems - put forward new problems", thus to form a spiral-up problem system, and ultimately to achieve the teaching purposes of solving the problems. Now the "problem-oriented" teaching mode is as follows:

\section{A. Multiple intelligence theory}

The multiple intelligence theory is an "Inherent Constructive" view of learning, emphasizing that everyone understands the knowledge in their own way and construct their own knowledge. This theory was proposed by Howard
Gardner, a psychological development expert at Harvard University's Institute of Education, in 1983 [2], representing a new theory concerning the human intelligence and intelligent pluralism. In other words, human intelligence should include the following seven aspects: language intelligence, music intelligence, mathematical logic intelligence, spatial intelligence, physical movement intelligence, interpersonal intelligence and intellectual self-understanding. Thus, intelligence in Gardner's theory is defined as: "the intelligence is an important ability to solve problems in a particular cultural context or society or to produce products."

\section{B. Structural learning theory}

The structural learning theory, also known as Constructivism Learning Theory, aims to develop students' ability to study through their lives in the new era, and to enable the students to master a learning process through self-analysis and effectiveness evaluation and to have the ability to reflect and criticize and the innovate spirits further to reflect the creativity and sustainability of learning [3]. The teaching subject is the same, but the teaching focus is shifted from the teacher to the student, and the teaching process is required to change the traditional knowledge view, learning view, teaching view, the student view and the teacher view. This theory argues that knowledge is not taught by teachers, but supplied by other people (including teachers and learning partners) in a certain context, namely, social and cultural backgrounds, and use necessary learning materials to acquire the learning meaning through the construction.

\section{Multidisciplinary integration teaching}

Multidisciplinary integration refers to the integration of the curriculum objectives, teaching content and teaching methods of the relevant subject curriculum without changing the names of the curriculums so as to achieve the goal of mutual penetration and discipline integration [4]. The types of the disciplinary integration can be divided into: goal integration, knowledge content integration, training goal integration and research method integration. For example, in terms of biomedical detection technology teaching, the scope from the study of human biological parameters to the study of medical diagnostic instruments is involved in the knowledge related to sensor and electronic technology, so that the relevant knowledge points of the two curriculums can be integrated; another example is that the curriculum related to the image processing curriculums and biological signal processing are involved in the theory and method of digital signal processing, so the two curriculums may find a fit point in the digital signal processing, which reflects the complementary relationship between the curriculum [5]. It can be seen that the research methods of the engineering disciplines can realize interdisciplinary teaching integration through knowledge transfer, application reorganization and method transformation.

\section{PRoblem-ORIENTEd CURRICULUM DESIGN OF BILINGUAL CURRICULUM IN ENGINEERING}

Based on the above-mentioned problem-oriented theories, and in combination with the professional characteristics of the bilingual curriculum in engineering, the following design is 
made on the teaching process, the selection of teaching materials and the evaluation criteria.

\section{A. Auxiliary bilingual teaching mode}

Auxiliary bilingual teaching mode is also called transitional bilingual teaching mode. Under this mode, the Chinese is taken as the main teaching language throughout the teaching activities. The main teaching materials and teaching courseware are made in Chinese and English, but the core concepts and deduction of the classroom teaching links should be explained in Chinese [6-7]. Therefore, this mode requires a low level of foreign language of the teachers and students: the teachers should be proficient in the core concepts in Chinese and English during lesson preparation, while the students should achieve level of College English Test Band 4.

TABLE I. TEAching ElEMENTS Distribution of AuXILIARy BiLINGUal Teaching Mode

\begin{tabular}{|c|c|c|}
\hline Chinese Mode & $\begin{array}{c}\text { Chinese-English Bilingual } \\
\text { Mode }\end{array}$ & English Mode \\
\hline Chinese references & Courseware PPT & English references \\
Practical teaching & & \\
Curriculum design operations & & \\
Curriculum tutoring & & \\
Curriculum assessment & & \\
\hline
\end{tabular}

\section{B. Mixed bilingual teaching mode}

Mixed bilingual teaching mode is more popular in the bilingual teaching process. Under this mode, the teaching materials in the teaching activities will adopt two languages in mixed mode: the courseware, teaching materials, experimental instructions and exercises are made in English for the main teaching, while the references in Chinese may be selected to be the supplementary teaching materials for the auxiliary teaching. Meanwhile, the proportion of foreign language in the classroom teaching should be raised, and it should pay attention to the balance of the Chinese and English in classroom teaching. The teachers should adjust the proportion of teaching in Chinese and English according to the curriculum content and the students' reaction. At the same time, they actively use the second classroom to strengthen the contact and communication between both sides and also adopt heuristic education and interactive teaching mode to add main language extracurricular teaching activities in English, like lectures, innovative experiments, online $\mathrm{Q} \& \mathrm{~A}$ and group discussions etc. through which to train students' professional English application ability. Under this mode, the teachers should increase the proportion of English during lesson preparation; especially add the contents in full English in the second class, while the students should achieve the level above College English Test Band 4.

TABle II. Teaching Elements Allocation of Mixed Bilingual Teaching Mode

\begin{tabular}{|c|c|c|}
\hline Chinese Mode & Chinese/English Mode & English Mode \\
\hline Chinese references & Courseware PPT & English references \\
\hline Practical teaching & Curriculum tutoring & Tutorials \\
\hline Curriculum design operations & & \\
\hline Curriculum assessment & & \\
\hline
\end{tabular}

\section{Submerged bilingual teaching mode}

It is also known as forced adaptive bilingual teaching mode. The mode makes the foreign language throughout the teaching activities; the teaching materials should adopt to be original in foreign language, and the proportion of the foreign language used in teaching accounts for over $85 \%$. The teaching mode aims to maximize the creation of a teaching environment in foreign language, and to drive the students and teachers to grasp the opportunity to express, think, analyze and solve problems in foreign language. The mode, forcing both sides to use foreign language, is conducive to improving students to adapt to the bilingual teaching environment. Meanwhile, this mode has higher requirements against the both sides in teaching: the teachers should have not only good professional education quality, but also the ability to have the initiative to start student needs and give play to the students' subjective initiative. But it is worth noting that if both sides' foreign language application ability cannot meet the requirements, the mode will produce adverse effects, that is, it cannot improve the effect of the ability of foreign language applications, but may become part of the burden of students to cause the students being weary of studying, rejecting the classroom and other adverse effects. 
TABlE III. Teaching Elements Allocation of Submerged Bilingual Teaching Mode

\begin{tabular}{|l|c|c|}
\hline Chinese Mode & Chinese/English Mode & English Mode \\
\hline Chinese references & Courseware PPT & English references \\
& Curriculum tutoring & Tutorials \\
& Practical teaching & \\
\hline
\end{tabular}

\section{Hierarchical bilingual education mode}

Based on the different levels of the teaching objects, and to meet the learning needs of the students on all levels, a hierarchical bilingual teaching mode can be adopted. This teaching mode means "Ability-Driven Education" teaching mode, which realizes the differentiated teaching based on the learning needs, interest orientation and receptivity of the different educational objects. The training objectives in different basic education stages and trained talents through higher education should have the knowledge system, innovation and sustainable development; especially for engineering professionals, innovation ability training is particularly important [8-9]. Therefore, the bilingual teachers of engineering technology curriculums should have the educational philosophy of "Ability-Driven Education". The hierarchical education is a concrete manifestation of this educational philosophy, and is currently used in many teaching activities of the university curriculum, like English curriculums adopting hierarchical education, individualized teaching plan development etc. Specifically speaking, the different bilingual teaching modes correspond to the education groups at different levels; for the teaching arrangements, keep the minimum requirements and strive to make improvement; the training of professionals based on the basic bilingual ability is accompanied with training of competitive international elite talents.

\section{CONCLUSION}

The emergence of the bilingual teaching is an inevitable trend of global integration, international internationalization and educational reform \& development; at the same time, in the context of implementing a series of "Step Out" strategies in China, bilingual teaching reform becomes necessary and urgent as the most basic condition. However, there are no uniform standards in the ideas, teaching methods and assessment modes of the bilingual teaching in different subject areas. In the future, the relevant theories and methods of the bilingual teaching in different disciplines can be put forward through multidisciplinary coordination so as to enhance the bilingual level and effect as a whole.

\section{REFERENCES}

[1] Ge Hongjuan. Bilingual Teaching Mode and Practice of Engineering Technology Curriculums [J]. Journal of Civil Aviation Flight University of China, 2004, 15 (6): P21-23.

[2] Chen Chunyang. Discussion on the Application of Multiple Intelligence Theory in English Teaching [J]. Vocational Technology, 2008 (9): P5051.

[3] Wang Pei, Kang Tinghu. Review of the Constructivistic Theory of Learning [J]. Teacher Education Research, 2004, 16 (5): P17-21.

[4] Du Yumin. Changes in the Way of Teaching and Learning of "Multidisciplinary Theme Integration" Curriculum [J]. Modern Teaching, 2014 (Z3): P112-113

[5] Yang Hui, Yu Chunying. Discussion on the Problem Orientation in Teaching [J]. China Market, 2014 (35): P179-180.

[6] Li Miao. The Application of Problem-Oriented Learning Method in Chemistry Teaching of New Curriculum Reform [J]. Tianjin Education, 2015 (12): P58-59.

[7] $\mathrm{Hu}$ Xiaoyong, $\mathrm{Hu}$ Xiaoli and Xie Dandan. Research on ProblemOriented Strategies to Promote Online Learners' Cognitive Skills [J]. Distance Education Journal, 2011 (03): P21-26.

[8] Huang Huijuan. Review of Problem-based Learning Implemented in Foreign Teacher Education [J]. Education and Teaching Research, 2013, 27 (8): P19-22.

[9] Ellen Johnson. Bilingual Education in the 21st Century: A Global Perspective [J]. Language in Society, 2013, 42(3):P344-345. 